\title{
EL MÉXICO INDÍGENA EN DOS CUENTOS DE OCTAVIO PAZ
}

\author{
POR \\ José Clemente Carreño Medina \\ Truman State University
}

Los mexicanos, especialmentelos escritores mexicanos, ... sobresalimos en el cumplimiento del precepto "hay que enterrar bien a los muertos". Somos los mejores enterradores del continente.

-Octavio Paz

En la segunda sección de ¿Águila o sol? (1951) intitulada "Arenas movedizas", Octavio Paz alude a la violencia ideológica del mestizaje que ha justificado la identidad nacional a través de dos cuentos: "El ramo azul" y "Cabeza de Ángel”. ${ }^{2}$ Ambos relatos se distancian de la visión pasiva con la que el autor entiende las culturas precolombinas en obras como El Laberinto de la soledad (1950) y "Postdata" (1969). En estos ensayos Paz observa al mexicano contemporáneo atrapado en sí mismo, incapaz de liberarse del trauma de su doble origen que lo ha dejado sin saber quién es. La respuesta es la apertura, la salida al exterior a través de la universalidad hispánica de la que el mexicano es heredero gracias al mestizaje cultural. Pero la presencia indígena es discordante con los paradigmas de esa ideología; ${ }^{3}$ de ahí que el "indio" devenga representación

1 Aquí utilizo la edición de Alianza Cien (1991) en la que se publica la sección de "Arenas movedizas" junto con la "Hija de Rappaccini". No obstante, véase la bellísima edición ilustrada de Gabriel Pacheco publicada en el 2014 por el Fondo de Cultura Económica con motivo de las celebraciones del centenario del natalicio del poeta.

2 En una carta fechada el 20 de septiembre de 1949, Octavio Paz le informa a Alfonso Reyes que tiene lista una colección de poemas en prosa. Esta fue una de las primeras referencias que Paz hace de este libro. Véase Anthony Stanton, Correspondencia Alfonso Reyes / Octavio Paz (106-07).

3 Más allá de la ineficacia del proyecto de modernización que propone el mestizaje, la enunciación que el poder hace de éste para imponer su control social es lo que se debe analizar; es decir, siguiendo a Slavoj Žižek, se está "dentro del espacio ideológico en sentido estricto desde el momento en que este contenido -'verdadero' o 'falso' (si es verdadero, mucho mejor para el efecto ideológico)- es funcional respecto de alguna relación de dominación social ... de un modo no transparente: la lógica misma de la legitimación de la relación de dominación debe permanecer oculta para ser efectiva" (15, énfasis en el original). En suma, mentir con la construcción de una "verdad". 
mítico-psicológica alejado de su realidad social. En este sentido, lo que aquí propongo es observar cómo esta doble representación fantasmagórica que Paz elabora en su ensayística del mundo indígena se violenta en los dos cuentos arriba mencionados; ${ }^{4}$ pues los modelos culturales precolombinos no se corresponden a los de la modernidad occidental. En consecuencia, el "indio" deja de ser esa representación inmóvil y lejana del trauma de la Conquista para convertirse, ya no solo en el personaje exótico que se construye a partir de la Revolución, sino también en la representación activa del "hombre salvaje" que debe ser blanqueado por medio el mestizaje. ${ }^{5}$ De ahí que resulte necesario admitir, siguiendo a Marco Thomas Bosshard, "la existencia de modernidades múltiples y alternativas, de modernidades muy diferentes de la modernidad occidental normativa" (11) en las que el indígena juega un papel activo y creador en la desterretorialización y reterritorialización de la escritura, siguiendo a Deleuze y Guattari, de su realidad inmediata más allá del Otro relegado al exotismo y al folclore. ${ }^{6}$

De acuerdo con Anthony Stanton, ¿Águila o sol? tuvo una recepción casi nula en su primera edición lo mismo en México que en Hispanoamérica debido la dificultad de género: poemas en prosa. ${ }^{7}$ El poemario fue el punto de inflexión en la poética de Paz porque representa su acercamiento más profundo al surrealismo que marcaría gran parte de la estética de su futura obra así como su interpretación del Otro. ${ }^{8}$ No fue hasta su traducción parcial al francés por Jean-Clarence Lambert (1957), y luego su traducción total al inglés por Eliot Weinberger (1970), que el libro fue debidamente atendido. ${ }^{9}$ Para Paz, no obstante, ¿Águila o sol? "fue una excavación del subsuelo mítico de México, al mismo tiempo que una autoexploración en mi propio subsuelo. Una tentativa por crear un mundo de imágenes en el que se fundiese la sensibilidad moderna con la antigua, las imágenes del México enterrado con las cosas del mundo moderno" (Cuarenta años

4 De acuerdo con Marco Thomas Bosshard, "la utopía surrealista se convierte ... en fantasmagoría: el exotismo persiste obstinadamente ..." (97).

Véase Roger Bartra, El salvaje en el espejo (13).

6 Véase Gilles Deleuze y Félix Guattari, Mil mesetas $(28,72)$.

¿Águila o sol? también representa la consumación, siguiendo a Sergio González Rodríguez, del "salto hábil del poeta al ensayista que funde el discurso filosófico con los vislumbres de lo invisible que desea encarnar ... La tarea difícil del poeta será evocar, conjugar, propiciar, desafiar el lenguaje para ampliar el mundo" (250-51).

8 El exotismo consciente de los surrealistas, generador de fetiches y fantasmagorías, tiene un elemento positivo porque, en palabras de Marco Thomas Bosshard, "sabiendo que no van a poder escaparse del exotismo, empiezan a abordar al Otro" (98). Asimismo, André Pieyre de Mandiargues comenta que Paz "era el único gran poeta surrealista activo en el mundo moderno, en el que los demás han dejado de lanzar llamas de fuego" (23).

9 A pesar de la escasa recepción del libro, en su artículo Stanton analiza los comentarios y reacciones sobre el libro de autores fundamentales como José Emilio Pacheco y Emir Rodríguez Monegal. Véase "Una lucha con el lenguaje" (11-14).

$111 \frac{\text { Revista Iberoamericana, Vol. LXXXV, Núm. 268, Julio-Septiembre 2019, } 951-962}{\text { ISSN 2154-4794 (Electrónico) }}$ 
71). ${ }^{10}$ En los dos cuentos de la sección de "Arenas movedizas" que aquí se analizan, se muestra no solo el "subsuelo" del México antiguo que Paz elabora a través del lenguaje mítico, ${ }^{11}$ sino también la inmensidad de su superficie multicultural que ha querido ser fallidamente modernizada con los paradigmas normativos del mestizaje ideológico. ${ }^{12}$

En "El ramo azul", el narrador describe la escena de un "indio" que por encargo de su novia, le quiere sacar los ojos azules a un fóraneo que se hospeda en el mesón de un pueblo de provincia. Debido al calor sofocante, el huésped se aventura a dar un paseo por las calles empedradas sin escuchar las recomendaciones del encargado del establecimiento: “-¿Onde va, señor? ... todo ya está cerrado. Y no hay alumbrado aquí. Más le valiera quedarse" (8). La falta de luz es la primera referencia que la narración hace sobre el binomio civilización (el mestizo) vs bararie (la comunidad indígena). El personaje ignora la advertencia y se adentra en la oscuridad en la que pronto se ve sorprendido por el "indio" dispuesto a cumplir el encargo de su pareja: "-No tenga miedo, señor. No lo mataré. Nada más voy a sacarle los ojos ... Me volví. Era pequeño y frágil. El sombrero de palma le cubría medio rostro. Sostenía con el brazo derecho un machete de campo, que brillaba con la luz de la luna" (9). En la última escena, el "indio", recatado, desiste de sus intenciones porque el foráneo tenía razón: no tenía ojos azules. La llama de un fósforo le salva la vida:

El resplandor me hizo entrecerrar los ojos. Él apartó mis párpados con mano firme. No podía ver bien. Se alzó sobre las puntas de los pies y me contempló intensamente. La llama me quemaba los dedos. La arrojé ... Froté otro fósforo y lo acerqué a mis ojos ...

10 Para José Francisco Conde Ortega, sin embargo, “Arenas movedizas” puede "identificarse con la vía iluminativa. Cuando ha pasado el proceso de expiación o de aprendizaje, se avizora el territorio por conquistar ... Entiende sus influencias, ... y descubre que las que han permanecido en él son voces americanas. Creo que no es aventurado afirmar que Borges, Macedonio Fernández y Neruda se advierten en los textos de este apartado" (26).

11 El lenguaje mítico-poético en Paz, es inseparable del lenguaje político. Véase Christopher Domínguez Michael, "La letra y el centro: los intelectuales y el poder" (139). Esta imposibilidad de separar ambos discursos es lo que paradójicamente se celebra en la obra de Paz, pero al mismo tiempo reduce la realidad social, en el caso del mundo indígena contemporáneo, al discurso ahistórico del mito. De acuerdo con Ignacio Sánchez Prado, Paz observa el discurso mítico como base de la identidad porque entiende que "la literatura y, sobre todo, la poesía es el discurso que permite poner a la modernidad en cuestión, es decir, la producción que permite espacios de libertad contra la homogeneización de sujetos implícita en las ideologías del Estado" (86).

12 En este sentido, John Beverly sugiere al analizar el pensamiento de Gramsci "people are essentially multicultural ... that is, multiculturalism is necessary rather than a contingent aspect of its identity as such. It does not mean, therefore, the generalization of the principle of multiculturalism to the whole social space, such that existing economic, racial, class, and gender differences ... require market liberalism for their expression" (57). En otras palabras, la multiculturalidad es el respeto a las diferencias sin buscar una homogeneización o síntesis; es decir, ir contra el discurso oficial que define la identidad nacional.

$111 \frac{\text { Revista Iberoamericana, Vol. LXXXV, Núm. 268, Julio-Septiembre 2019, } 951-962}{\text { ISSN 0034-9631 (Impreso) }}$ 
Me hinqué con una mano me cogió por los cabellos, echándome la cabeza hacia atrás. Se inclinó sobre mí, curioso y tenso, mientras el machete descendía lentamente hasta rozar mis párpados ... Me soltó de improviso-Pues no son azules señor. Dispense. (10)

La imagen sugiere que la luz venció a la oscuridad; la civilización derrotó a la barbarie. La violencia que se le atribuye al "indio" justifica la construcción del sujeto colonial que legitima al mestizo como representante de la modernidad a la que México aspira. ${ }^{13}$ El opresor ya no es el que viene de afuera sino el habitante local. Hay una inversión entre el sujeto hegemónico y el sujeto colonial. El "indio" es ahora el que no se abre, el sujeto cerrado, el agente activo que penetra al Otro: el indio deviene chingón.

El contraste que la narración propone refuerza el discurso del mestizaje que Paz defendió a pesar de su rechazo al discurso ideológico de lo nacional. ${ }^{14}$ La mestizofilia, como lo propone Agustín Basave Benítez, "puede definirse ... como la idea de que el fenómeno del mestizaje ... es un hecho deseable ... la tendencia a vincular mestizaje y mexicanidad responde esencialmente a una búsqueda de identidad nacional" $(13,14) .{ }^{15}$ El mestizo ha cumplido esa enunciación discursiva como el representante más alto de la mexicanidad. No obstante, este discurso ha promovido la adaptación violenta no solo del "indio", sino de todas las heterogeneidades culturales, como las afro y judíomexicanas por ejemplo, al proyecto nacional a través de su silenciamiento y no por medio de una participación activa como lo pensaba Fernando Ortiz en la construcción de una nueva realidad social. ${ }^{16}$ Se ha mantenido entonces una relación de poder entre ambas culturas, entre el yo hegemónico y el otro colonizado, ${ }^{17}$ lo que hace del paradigma del mestizaje un discurso caduco e ineficiente para la heterogeneidad étnica y cultural del México contemporáneo. ${ }^{18}$

13 Aníbal Quijano entiende el pensamiento colonial, o de colonialidad, como un modelo global de poder basado en la superioridad racial europea, que se originó en el siglo XVI con la Conquista y que se prolonga en América Latina hasta la actualidad. Véase "Colonialidad del poder” (201).

14 "Octavio Paz - dice Jesús Silva-Herzog Márquez- lo vio con claridad: ideología y nacionalismo son los precipicios de la identidad. Ideas cerradas que decretan la comunión obligatoria, coartadas de la mediocridad a la caza de impuros" (89).

15 En este sentido, Josefina Saldaña-Portillo comenta: "In the trope of mestizaje, the Indian is posited as an originary movement in an evolutionary Mexican history. Biologically, the Indian dissolves into the formulaically more progressive mestizo" (407).

16 Fernando Ortiz entiende que la transculturación es un proceso donde una nueva realidad original se gesta, es decir una transición entre dos culturas que equitativamente activas contribuyen a la formación de una nueva realidad. Véase "Contrapunteo del tabaco y el azúcar".

17 Para Levinas: "The Other as Other is not only an alter ego: The Other is what I myself am not ... The Other is, for example, the weak, the poor ... whereas I am the rich or the powerful" (83).

18 El discurso del mestizaje, de acuerdo con Antonio Cornejo Polar, no explica la heterogeneidad étnica de México ni de América Latina, pues "falsifica de manera más drástica la condición de nuestra cultura y literatura" (341). 
Octavio Paz afirma en El laberinto que el mexicano "no quiere ser indio, ni español. Tampoco quiere descender de ellos. Los niega. Y no se afirma en tanto que mestizo, sino como abstracción: es un hombre. Se vuelve hijo de la nada. Él empieza en sí mismo" (225). La negación del origen español es precisamente lo que él trata de reivindicar a través de una crítica freudiana. ${ }^{19} \mathrm{Si}$ el mestizo parte de cero, debía partir como heredero activo que supone la universalidad española y superar su pasado precolombino. El laberinto explica las contradicciones del mexicano a partir de su doble herencia indígena y española en la que el mestizaje se convierte -siguiendo a Sergio González Rodríguez- en "condena y camino de salvación” (235).

En la recreación del relato de "Cabeza de Ángel" hay un fluir de consciencia surrealista más cercana a la pesadilla que al sueño a través de la voz narrativa. Esto se hace más evidente por la ausencia de signos de puntuación y de división de párrafos, lo que intensifica el fluir de conciencia que describe imágenes trágicas en la narración.

La narradora se adentra en una vieja casa en la que contempla el paisaje de varios cuadros; al asomarse a uno de ellos como en una ventana, un grupo de moros le cortan la cabeza: "salía de mi cuello un chorro de sangre que regaba el suelo como una cascada roja y del suelo nacían multitud de florecitas rojas" (53). Después un ángel baja para colocarle su cabeza, pero al no tener éxito, la narradora abandona el paisaje: "volví a México y me metí en el corral de mi casa en donde había mucho sol y polvo ..." (53). Su madre no le cree y se muestra indiferente a su tragedia; la reprende mandándola al rincón de los castigos de la casa. Ahí, molesta, deseando la muerte de su progenitora, la pared se abre y de pronto la narradora:

estaba al pie de un pirú que estaba junto a un río seco y había unas piedras grandes que brillaban al sol ... de pronto ... en la tierra vi otra vez mi cuerpo sin cabeza y mi tronco ya estaba cicatrizando y sólo le escurría un hilo de sangre que formaba un charquito en el polvo ... me puse a buscar mi cabeza y no aparecía y no podía ni siquiera llorar y como no había nadie en aquel paraje me eché a andar por un llano inmenso ... hasta que llegué a un jacal de adobe y me encontré a un indito que allí vivía ... (53-54)

El personaje se alegra cuando un "indito" le ofrece varias cabezas. Al no encontrar ninguna que le quede correctamente el "indito" le dice:

\footnotetext{
${ }_{19}$ La obra ensayística de Paz, en especial el Laberinto, adopta el valor del intelectual que Freud pondera en Moisés y la religión monoteista. La crítica intelectual que Freud propone se fundamenta en la abstracción, en la destrucción de imágenes que comprometen la objetividad del critico. De acuerdo con Rubén Gallo, "El laberinto reafirma la convicción freudiana de que el desarrollo del intelecto requiere un rechazo de las imágenes a favor de la abstracción [...] Paz asocia las imágenes con la complacencia intelectual: lo visual bombardea los sentidos con un exceso de información y deja muy poco a la imaginación" (10).
}

$111 \frac{\text { Revista Iberoamericana, Vol. LXXXV, Núm. 268, Julio-Septiembre 2019, } 951-962}{\text { ISSN 0034-9631 (Impreso) }}$ 
$[\mathrm{N}]$ o se amuine niña vamos al pueblo a cortar una cabeza que le acomode ... llegamos al pueblo y en la plaza había una niña que estaba martirizando unos señores vestidos de negro como si fueran a un entierro ... la niña estaba muy tranquila y entonces el indito se abrió paso y cuando todos estaban descuidados le cortó la cabeza a la niña y me la puso y me quedó muy bien y yo di un salto de alegría porque el indito era un ángel ... (54-55)

Es significativa la violencia que la narración le atribuye al "indito" en esta escena en su afán de restituir la cabeza de la narradora que sugiere representar a la joven nación mexicana. El personaje indígena se presenta como salvador, como un ángel guerrero que le devuelve a ese México parte de su herencia hispánica que había sido arrebatada a causa de su degollación a manos de los moros, así como por la indiferencia de un nacionalismo estéril de la clase política representada por unos señores vestidos de negro "como si fueran a un entierro y uno de ellos leía un discurso como en el cinco de Mayo y había muchas banderas mexicanas en el Kiosko y una marcha y era como una feria había montones de cacahuates y de jícamas y cañas de azúcar y cocos y sandías ..." (54-53).

La descripción anterior muestra la preocupación de Paz por ese otro México indígena que la clase gobernante ha mantenido en el subdesarrollo político y económico tras la institucionalización de los ideales revolucionarios. Esta clase política es, paradójicamente, el ogro filantrópico al que Paz representó en el servicio diplomático hasta 1968 y que, como se vio en "Postdata", criticó duramente pero sin cuestionar su legitimidad, es decir, sin cuestionar su derecho al poder como heredera de la Revolución Mexicana. ${ }^{20}$ De ahí su defensa del proyecto mestizofílico a pesar de su "pasión crítica" contra el Estado.

La ilegitimidad de la narradora sin cabeza que Paz sugiere en la narración, se afilia a la violencia que ya no comete Cortés sino el "indito" a través de la degollación de una niña inocente. En esta imagen, el "indio" deviene verdugo, piedra de tropiezo para un proyecto de nación moderno que hay que superar con la revalorización de lo español como herencia universal. Solo así se entendería el interés de Paz por restituir la figura maltratada de Hernán Cortés que, en palabras de José Luis Martínez, “inició el mestizaje de pueblos y culturas, que será uno de nuestros rasgos permanentes" (10).

Guillermo Sheridan sugiere que la narradora del cuento es la prima de Paz, María Luisa, quien solía visitar la vieja casa del abuelo don Ireneo. Según Sheridan:

${ }^{20}$ Paz creyó, de acuerdo con Christopher Domínguez Michael, "en la legitimidad y el carácter esencialmente progresista del Estado de la Revolución Mexicana. Incluso en el Laberinto de la Soledad ... hay párrafos en que uno distingue no sólo la voz del gran ensayista sino también la del funcionario público, que no sin críticas y pesadumbres está diciendo que la Revolución Mexicana valió la pena y que el Estado mexicano nacido de ella, que veinte años después será 'el ogro filantrópico', es una avance civilizatorio en la historia de México" (136). 
“[r]ealidad y ajenidad, tedio y cerrazón: la casa es una oquedad que espera. Su naturaleza deshabitada es también metáfora de sus habitantes; los espacios huecos reciprocan la cansada melancolía del abuelo ..."(24). No obstante, la imagen de la casa sugiere la representación de las constantes luchas ideológicas que prevalecieron en su seno familiar: el abuelo porfirista y el padre zapatista. Paz experimenta en su niñez esta contradicción ideológica que más tarde construiría su doble visión liberal-romántica. ${ }^{21}$

En ambos relatos pacianos existe un paralelismo con las narraciones que escribiría un par de años después Juan Rulfo: El llano en llamas (1953) y Pedro Páramo (1955), pues en ellas abundan los ambientes oscuros y paisajes desolados. Sin embargo, quizá la similitud más significativa sea la de la violencia y su experimentación como algo sistémico, siguiendo a Slavoj Žižek, ${ }^{22}$ para el mexicano. En "El ramo azul”, el narrador dice: "Desperté, cubierto de sudor. Del piso de ladrillos rojos, recién regado, subía un vapor caliente" (7). Asimismo, en "Cabeza de Ángel” la narradora asegura que: "Apenas entramos me sentí asfixiada por el calor y estaba como entre los muertos ..." (51). Ambos autores desarrollan sus narraciones dentro de un ambiente de penitencia; es decir, México visto como purgatorio, como el lugar de los chingados. ${ }^{23}$

Paz ve la cultura indígena como la chingada por considerarla abierta y pasiva. Esto se contrapone a su visión eurocéntrica cerrada y activa; observa que "[1]o chingado es lo pasivo, lo inerte y abierto, por oposición a lo que chinga, que es activo, agresivo y cerrado. El chingón es el macho, el que abre. La chingada, la hembra, la pasiva pura, inerme ante el exterior ... La idea de violación rige oscuramente todos los significados" (Laberinto 214). Asimismo expone la relación desigual entre ambas culturas con dicha dualidad en la que la Malinche sale perdiendo. De ser así, ¿se tendría que ver a Paz afiliado con los que chingan? ¿Se llegaría a decir entonces que Paz deviene chingón? Si Paz intentó destruir el mito negro de Hernán Cortés, el chingón por antonomasia del “indio" para trazar un puente con la tradición española y, al mismo tiempo, construyó una compleja interpretación mítica de la Malinche como la madre chingada de los mexicanos, se podría responder afirmativamente a tal conjetura.

Roger Bartra analiza desde otra perspectiva el mito de la Malinche y hace un paralelismo con el de la Virgen María. De acuerdo con Bartra:

${ }^{21}$ Quizá por eso Maarten Van Delden haya visto significativo en Paz "how he has tried to straddle this divide, to take on both the cause of the Enlightenment and the cause of Romanticism" (473).

22 De acuerdo con Slavoj Žižek, la opresión que ejerce el poder sobre una sociedad, ya sea a través del Estado o cualquier otro aparato rector, destruye toda capacidad creadora que no se ajuste a sus lineamientos homogeneizadores. Véase "El espectro de la ideología".

23 La generación de Paz y Rulfo es -como afirman Juan Antonio Rosado y Adolfo Castañón- "la primera generación plena, desgarradoramente moderna, crítica del México del siglo XX ... Es una generación a la que le ha tocado trascender ... las polémicas nacionalistas que sangraron a la generación anterior: las cuestiones de la identidad política y cultural, las tensiones y tentaciones de la vocación literaria ..." (263).

$111 \frac{\text { Revista Iberoamericana, Vol. LXXXV, Núm. 268, Julio-Septiembre 2019, } 951-962}{\text { ISSN 0034-9631 (Impreso) }}$ 
Sin duda las mujeres regaladas perdieron muy pronto su virginidad, pero lo mismo se podría decir de la imagen que recibieron los indígenas ... Tanto traicionó la Malinche a su pueblo como la Virgen al suyo, pues las dos se entregaron y su originalidad quedó mancillada: la primera dio inicio a la estirpe de mestizos, la segunda renació como Virgen india y morena. (Jaula de la melancolía 193)

Bartra contempla en el mito la mutua influencia equitativa entre ambas culturas. Así se aproxima al concepto de transculturación de Fernando Ortiz en el sentido de intercambio, pero mestizaje al fin. Las dos razas se contaminaron por igual tanto racial como culturalmente, es decir, las dos civilizaciones se chingaron. Esta imagen se opone a la visión pasiva de la Malinche que Paz propone en su interpretación.

Asimismo, Margo Glantz observa a una Malinche activa y poseedora del poder de la palabra. Pues su función es la de faraute, es decir, la de ser intérprete. De acuerdo con Glantz, "Malinche ha demostrado que sabe las dos lenguas ... se ha entremetido entre los españoles y los indios y ha enseñado su calidad: es por lo tanto bulliciosa" (126), y respetada por los indígenas al llamarla Malintzin, como por los españoles al llamarla doña Marina.

Tanto en su ensayística como en sus relatos, Paz entiende el mundo indígena como discordante con el Enlightenment Project al que él pareció afiliarse a pesar de su admiración cultural por el mundo precolombino. ${ }^{24}$ En los dos relatos arriba analizados, el indígena deja de ser una representación exótica para convertirse en un agente activo, lo que difiere drásticamente de la visión que el mismo Paz propone en El laberinto y en Postdata. Si bien es cierto que Paz critica la violencia sistémica que ha representado el ogro filantrópico para la heterogeneidad cultural de México, es igualmente innegable la inversión que construye desde el "indio" como sujeto pasivo hasta el "indio" como sujeto activo o chingón a través de la violencia que, en su esencia, la ideología del mestizaje propone inútilmente disolver.

La modernización integral de México es aún la asignatura pendiente como lo sigue mostrando la obra de Paz; ${ }^{25}$ pero no se vislumbrará mientras se continúen implementando políticas que no trasciendan, que no vayan más allá de las fantasmagorías ni los

24 Según Jürgen Habermas, el "Enlightenment Project" implica desde la "formation of capital and the mobilization of resources; to the development of the forces of production and the increase in the productivity of labor; to the establishment of centralized political power and the formation of national identities; to proliferation of rights of political participation, of urban form of life, and of formal schooling; to the secularization of values of life, and so on" (2). Asimismo, Carlos Monsiváis ha dicho acertadamente que la "identidad entre otras cosas, es el consuelo de muchos, la resignación compartida ante las carencias, la solidaridad de la frustración” (301).

25 De acuerdo con Julio María Sanguinetti, “el gran desafío de América Latina es la modernización, porque o nos modernizamos o nos modernizan, y a veces nos modernizan mediante la avalancha que nos viene de afuera por la ciencia, por la tecnología, por las multinacionales que están más allá de la frontera" (121).

$111 \frac{\text { Revista Iberoamericana, Vol. LXXXV, Núm. 268, Julio-Septiembre 2019, } 951-962}{\text { ISSN 2154-4794 (Electrónico) }}$ 
contenidos culturales predeterminados de herencia europea que no se ajustan a la multiculturalidad mexicana, ${ }^{26}$ ni ataquen de fondo la voraz corrupción e impunidad gubernamental. La modernidad mexicana sigue siendo un mañana, un hoy que no llega a pesar de que en la década de los noventa del siglo pasado pareció finalmente abrazarse a ella; a pesar de que el país haya intentado, fallidamente, transformarse en un mosaico de la diversidad. ${ }^{27}$ México se encuentra en un callejón sin salida; sigue condenado a ser moderno como lo vio Paz con claridad. La cuestión palpitante es, en suma, apostar por modernidades múltiples que posibiliten la reterritorialización de los espacios usurpados por los paradigmas ideológicos que han sustentado la cruel modernidad mexicana.

\section{BiBLIOGRAFÍA}

Agamben, Giorgio. El hombre sin contenido. Margaretto Kohrmann, trad. Barcelona: Altera, 2005.

Bartra, Roger. El salvaje en el espejo. México, D.F.: Coordinación de Difusión Cultural, Coordinación de Humanidades, Universidad Nacional Autónoma de México, 1992. La jaula de la melancolía: Identidad y metamorfosis del mexicano. 14ta ed. México, D.F.: Grijalbo, 2007. coord. Anatomía del mexicano. México, DF: Debolsillo, 2007.

Basave Benítez, Agustín. México mestizo: Análisis del nacionalismo mexicano en torno a la mestizofilia de Andrés Molina Enríquez. México, D.F: Fondo de Cultura Económica, 1992.

Beverly, John. "The Im/possibility of Politics: Subalternity, Modernity, Hegemony." The Latin American Subaltern Studies Reader. Ileana Rodríguez, ed. Durham: Duke UP, 2001. 47-63.

${ }_{26}$ Giorgio Agamben ha sugerido que el arte, y sobre todo el artista, es un hombre sin contenido, mientras que el crítico moderno se encarga de dárselo a través del juicio estético sin lograrlo, puesto que “dondequiera que el crítico encuentra el arte vuelve a conducirlo a su opuesto, disolviéndolo en el noarte y la sombra, como si para adorar al arte no tuviese otra opción más que celebrar una especie de misa negra en honor al deusinversus del no arte" (77). Esta imagen que propone Agamben también establece un paralelismo con el eurocentrismo con que parte de las élites políticas e intelectuales observan a las culturas no occidentales.

27 Para José Carlos Castañeda, la década de los noventa y la alternancia en la presidencia de México en el año 2000, significó el cierre democratizador que se había abierto en 1968. Sin embargo, la actualidad política del país nos desengaña: el proceso democratizador continúa abierto. Lo cierto es que a partir de aquella década finisecular se confirma que, de acuerdo con Castañeda, "[y]a no existe lo mexicano como una prueba de la unidad nacional ..., sino la multiplicidad de voces que dan diversos perfiles y distintas tonalidades a un país, cada vez más cerca del mundo global y más lejos del territorio inhóspito de la identidad de la patria" (458). 
Bosshard, Marco Thomas. La reterritorialización de lo humano: Una teoría de las vanguardias americanas. Pittsburgh: IILI-Nuevo Siglo, 2013.

Castañeda, José Carlos. "Los noventa: Los años intempestivos". La literatura mexicana del siglo XX. Manuel Fernández Perera, coord. México, D.F.: Fondo de Cultura Económica/Consejo Nacional para la Cultura y las Artes / Universidad Veracruzana, 2008. 457-491.

Castañón, Adolfo y Juan Antonio Rosado. "Los años cincuenta: Sus obras y ambientes literarios". La literatura mexicana del siglo XX. Manuel Fernández Perera, coord. México, D.F.: Fondo de Cultura Económica / Consejo Nacional para la Cultura y las Artes / Universidad Veracruzana, 2008. 261-310.

Conde Ortega, José Francisco. “Octavio Paz; ¿Águila o sol?”. Casa del tiempo. Universidad Autónoma Metropolitana 1/2 (2014): 25-28.

Cornejo-Polar, Antonio. "Mestizaje e hibridez: Los riesgos de las metáforas. Apuntes." Revista Iberoamericana LXIII/180 (Julio-Septiembre 1997): 341-344.

Deleuze, Gilles, y Félix Guattari. Mil mesetas: Capitalismo y esquizofrenia. José Vázquez Pérez y Umbelina Larraceleta, trad. Valencia: Pre-Textos, 1997.

Domínguez Michael, Christopher. "La letra y el centro: Los intelectuales y el poder". Memorias de un homenaje: Octavio Paz, 1914-2014. México, D.F.: CONACULTA, 2014. 123-145.

Fernández Perera, Manuel, coord. La literatura mexicana del siglo XX. México: Fondo de Cultura Económica/Consejo Nacional para la Cultura y las Artes/Universidad Veracruzana, 2008.

Gallo, Rubén. "La crítica en Paz: abstracción y erotismo". La Gaceta del Fondo de Cultura Económica 519 (marzo 2014): 9-10.

Garganigo, John F., ed. Huellas de las literaturas hispanoamericanas. 2nd. ed. Upper Saddle River, NJ: Prentice Hall, 2002.

Glantz, Margo. "La Malinche: La lengua en la mano". Mitos mexicanos. Enrique Florescano, ed. México, D.F.: Aguilar, 1995. 119-137.

González Rodríguez, Sergio. "La literatura mexicana en los años cuarenta". La literatura mexicana del siglo XX. Manuel Fernández Perera, coord. México, D.F.: Fondo de Cultura Económica / Consejo Nacional para la Cultura y las Artes / Universidad Veracruzana, 2008. 203-259.

Guattarri, Félix, y Gilles Deleuze. Mil mesetas: Capitalismo y esquizofrenia. José Vázquez Pérez y Umbelina Larraceleta, trad. Valencia: Pre-Textos, 1997.

Habermas, Jürgen. The Philosophical Discourse of Modernity: Twelve Lectures. Frederick Lawrence, trad. 2da ed. Cambridge, MA: MIT, 1987.

Lander, Edgardo y Santiago Castro-Gómez, eds. La colonialidad del saber: eurocentrismo yciencias sociales: perspectivas latinoamericanas. Buenos Aires: CLACSO, 2000. Lévinas, Emmanuel. Time and the Other and Additional Essays. Pittsburgh: Duquesne UP, 1987. 
Mandiargues, André Pieyre. “Aigle ou Soleil?”. María Virginia Jaua Alemán, trad. La Gaceta del Fondo de Cultura Económica 519 (marzo 2014): 11-14.

Martínez, José Luis. Hernán Cortés. 2nd ed. México: Universidad Nacional Autónoma de México/Fondo de Cultura Económica, 1990.

Monsiváis, Carlos. "La identidad nacional ante el espejo". Anatomía del mexicano. Roger Bartra, ed. 2nd ed. México, D.F: Debolsillo, 2007. 295-301.

Ortiz, Fernando. "Contrapunteo del tabaco y el azúcar". Huellas de las literaturas hispanoamericanas. 2da ed. John F. Garganigo, ed. Upper Saddle River, NJ: Prentice Hall, 2002. 454-462.

Paz, Octavio. “Cabeza de ángel”. Arenas movedizas. La hija de Rappaccini. México, D.F.: Alianza Cien, 1991. 51-55.

Cuarenta años de escribir poesía: Conferencias en El Colegio Nacional. Enrico Mario Santi, ed. Mexico, D.F: DGE/Equilibrista/El Colegio Nacional/ Consejo para la Cultura y las Artes, 2014.

El laberinto de la soledad. Enrico Mario Santí, ed. 11ma ed. Madrid: Cátedra, 2003.

"El ramo azul". Arenas movedizas. La hija de Rappaccini. México, D.F.:Alianza Cien, 1991. 7-10.

"Postdata". El laberinto de la soledad. Enrico Mario Santi, ed. Madrid: Cátedra, 2003 .

Quijano, Aníbal. "Colonialidad del poder, eurocentrismo y América Latina". La colonialidad del saber: eurocentrismo y ciencias sociales: perspectivas latinoamericanas. Edgardo Lander y Santiago Castro-Gómez, ed. Buenos Aires: CLACSO, 2000. 201-246.

Rodríguez, Ileana, ed. The Latin American Subaltern Studies Reader. Durham: Duke UP, 2001.

Rosado, Juan Antonio y Adolfo Castañón. "Los años cincuenta: Sus obras y ambientes literarios". La literatura mexicana del siglo XX. Manuel Fernández Perea, coord. México, D.F.: Fondo de Cultura Económica / Consejo Nacional para la Cultura y las Artes / Universidad Veracruzana, 2008. 261-310.

Saldaña-Portillo, Josefina. "Who's the Indian in Aztlán? Re-Writing Mestizaje, Indianism, and Chicanismo from the Lacandón. The Latin American Subaltern Studies Reader. Ileana Rodríguez, ed. Durham: Duke UP, 2001. 402-422.

Sánchez Prado, Ignacio M. "De la utopía a la migración: del legado de Alfonso Reyes y la evolución del latinoamericanismo en México". Intermitencias americanas: estudios y ensayos escogidos (2004-2010). México, DF: Universidad Nacional Autónoma de México, 2012. 79-93.

Sanguinetti, Julio María. "La democracia en el orbe iberoamericano". Memorias de un homenaje: Octavio Paz, 1914-2014. México, D.F.: CONACULTA, 2014. 101-122.

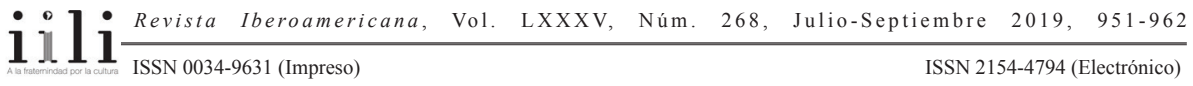


Silva-Herzog Márquez, Jesús. "Fanatismos de la identidad". Memorias de un homenaje: Octavio Paz, 1914-2014. México, D.F.: CONACULTA, 2014. 75-99.

Sheridan, Guillermo. Poeta con paisaje: Ensayos sobre la vida de Octavio Paz. México, D.F: Ediciones Era, 2004.

Stanton, Anthony. Correspondencia Alfonso Reyes/Octavio Paz:(1939-1959). México, D.F.: Fundación Octavio Paz, 1998.

"Una lucha con el lenguaje". La Gaceta del Fondo de Cultura Económica. 519 (2014): 11-14.

Van Delden, Maarten, “Essays". Latin American Literature. Verity Smith, ed. Londres: Fitzroy Dearborn Publisher, 2000. 471-473.

Žižek, Slavoj. Introducción. "El espectro de la ideología". Ideología. Un mapa de la cuestión. Mariana Podetti, trad. et al. Slavoj Žižek, comp. 2nd ed. Buenos Aires: Fondo de Cultura Económica, 2005. 7-41.

Palabras clave: Mestizaje, indio/indígena, fantasmagoría, el chingón/la chingada

Recibido: $\quad 22$ septiembre 2015

Aprobado: $\quad 23$ agosto 2016 